\title{
Survival analysis, consumer perception and physico-chemical analysis of low fat UHT milk stored for different time periods
}

\author{
Melanie Richards, Elna M. Buys, Henriëtta L. De Kock* \\ Department of Food Science, University of Pretoria, Pretoria, 0001, South Africa \\ melanie.richards@up.ac.za, elna.buys@up.ac.za, riette.dekock@up.ac.za, \\ *Corresponding author: Tel: +27 12 4203238; E-mail address: riette.dekock@up.ac.za
}

Survival analysis based on consumers' acceptance or rejection of milk of different storage ages, was used to validate the shelf life of low fat UHT milk in high density polyethylene (HDPE) bottles, as determined by a multivariate accelerated shelf life test (MASLT) in a prior study (Richards, De Kock, \& Buys, 2014). UHT milk samples between 120 and $290 \mathrm{~d}$ of storage were evaluated. On the basis of $50 \%$ of consumers rejecting the product, the shelf life of the UHT milk was estimated to be $214 \mathrm{~d}$, validating the shelf life of $211 \mathrm{~d}$ estimated by the MASLT. In addition to this, consumers were asked to complete check-all-that-apply (CATA) attribute questions and rate the acceptability of the milk. Physico-chemical and enzymatic properties of the UHT milk of various ages was also evaluated. The consumers noted positive sensory attributes more frequently in fresher milk samples with an increase in negative attributes with storage. Along with this, the hedonic scores for the UHT milk also decreased and physico-chemical and enzymatic reactions associated with the deterioration of UHT milk increased as the milk was stored for longer time periods.

\section{INTRODUCTION}

Ultra-high temperature processing (UHT) of milk results in a product with a long shelf life when stored at room temperature (Valero, Villamiel, Miralles, Sanz, \& Martinez-Castro, 2001). The high temperature of the UHT process $\left(140-145^{\circ} \mathrm{C}\right.$ for 4 $10 \mathrm{~s})$ and the long storage time can, however, result in changes in the sensory properties that can reach a limit beyond which the consumer will reject the product. Various enzymatic and physico-chemical reactions occur in UHT milk and are responsible for the development of various off-flavours, sedimentation, gelation and discolouration of the milk (Sieber, \& Bosset, 2001; Celestino, Iyer, \& Roginski, 1997; Shipe et al., 1978). Sensory shelf-life studies often consider product defects, such as 
rancid and oxidized flavour in milk (Lawless \& Claassen, 1993), as the critical attributes. These defects are, however, not always what determines the end of shelf life, but rather changes in the levels of the desirable attributes or a combination of the two (Garitta, Hough, \& Sánchez, 2004).

Although it is not expected that a product stored for several months should be exactly the same as the fresh standard, the sensory differences should be small enough for the acceptability of the product not to be altered significantly (Garitta et al., 2004). Trained sensory panels are able to detect very small differences in products that may be very useful in quality control or other tasks where the integrity of the product needs to be maintained (Hough, 1998; Moskowitz, 1998), but these variations may be irrelevant to the end-consumer. Consumers and trained panels could perceive the product differently (Ares, Barreiro, Deliza, Giménez, \& Gámbaro, 2010; van Trijp \& Schifferstein, 1995). Consumer data based on simple sensory concepts, such as discriminative tests, consumer preference, acceptance and liking, can therefore ensure a better understanding of how people perceive the sensory properties of food and also predict the actual marketplace behaviour (Ares et al., 2010). Shelf life estimation using consumer panels is important for microbiologically stable products

(Guerra et al. 2008), such as UHT milk. For such products the criteria for end of shelf-life will be determined less by food safety and more by the sensory quality of the food. Survival analysis has been applied in various areas of consumer research, including shelf life studies of different food products (Corrigan, Hedderley, \& Harvey, 2012; Curia, Aguerrido, Langohr, \& Hough, 2005; Gámbaro, Garitta, Giménez, Varela, \& Hough, 2004; Garitta et al., 2004; Hough, Langohr, \& Gómez, 2003). Consumers are either asked to accept or reject samples of different storage ages and the shelf life of the product is estimated as the time taken to reach a predetermined percentage of consumer rejections. The failure function $F(x)$ used in survival analysis can be defined as the probability of an individual failing before time $x$ is reached. The "individual" in sensory shelf life studies would not be the food itself, but rather the consumer. Therefore the failure function would be defined as the probability of a consumer rejecting a product at a time shorter than $x$. The focus of survival analysis used in shelf life studies is therefore not on the food product and its deterioration but rather on the probability of a consumer rejecting the product stored for a certain 
time. (Gámbaro, Ares, \& Giménez, 2006; Hough et al., 2003; Hough, Garitta, \& Gómez, 2005; Klein \& Moeschberger, 1997).

The objective of this study was to use survival analysis to determine the shelf life of low fat UHT milk in HDPE bottles. The shelf life was determined by consumers accepting or rejecting milk of various ages. Successful application of this methodology can be used as validation for the multivariate accelerated shelf life model developed by Richards et al. (2014). The multivariate acceleration factors of the milk was determined using this model and can be used to determine the shelf life of milk in a relatively short time period by storing the milk at abuse temperatures and then extrapolating the results to normal storage conditions. In addition, physico-chemical analysis, check-all-that-apply questions and hedonic scales were included to determine the physico-chemical properties, consumers' perception of the sensory attributes and consumers' liking of aroma, appearance, flavour and overall liking of the UHT milk of different ages, respectively.

\section{MATERIALS AND METHODS}

\subsection{Consumer evaluation}

Regular UHT milk consumers ( $\mathrm{n}=120,52$ males and 68 females) (Hough et al., 2007) were recruited and each consumer received 6 samples of low fat UHT milk $(2.1 \%$ fat $)$ that had been stored at $25^{\circ} \mathrm{C}$ for different time periods $(120,150,180$, 210, 240 and 290 d). Samples from the same supplier as for the MASLT study (Richards et al., 2014) were manufactured for each of the sampling times and stored at $25^{\circ} \mathrm{C}$. Freshly packed low fat UHT milk was collected and stored at $25^{\circ} \mathrm{C}$ until the day of evaluation (this would be the $290 \mathrm{~d}$ sample), after 30 days another batch of freshly packed milk was collected and stored at $25^{\circ} \mathrm{C}$ (this would be the $240 \mathrm{~d}$ sample). This was repeated to have samples for all the different storage times ready on the day of evaluation. As samples comprised different batches, a trained sensory panel ( $\mathrm{n}=11,9$ females and 2 males, aged 19 to 45 years) performed triangle tests to ensure that there was no significant difference between a sample of the one batch (kept at $5^{\circ} \mathrm{C}$ ) and that of the following batches. 
Milk samples $(50 \mathrm{~mL})$ were chilled in a refrigerator at $7^{\circ} \mathrm{C}$ after portioning and served at $15 \pm 1^{\circ} \mathrm{C}$ in random 3-digit coded glasses covered with foil. During the sensory evaluation consumers received numbered trays with samples served in an order determined by the Williams Latin Square design (Williams, 1949). General Good Sensory Practices (GSP's) (Lawless \& Heymann, 1998) were followed in the selection, preparation, and serving of samples to consumers.

Consumers were asked to answer "yes" or "no" to the question "Would you normally consume this product?" if they had purchased the product or it was served to them in a home situation. In addition to this the consumers were also asked to rate the aroma, appearance, flavour and overall liking on a 9 point hedonic scale (with 1 being "like extremely" and 9 being "dislike extremely") and provide a sensory profile of the different milk samples by considering the presence or absence of a list of check-all-that-apply (CATA) attributes appropriate in describing the UHT milk samples. Attributes for the CATA question included: caramel smell, cooked milk smell, fresh milk smell, sour smell, off smell, caramel taste, cooked milk taste, sweet taste, sour taste, off taste, creamy taste, bitter taste, dry mouth feel, metal taste, white colour and curdling. These attributes were selected from a list generated for UHT milk by a trained sensory panel (Richards et al., 2014). Filtered water was provided for neutralising and cleansing the palate before and between sample tasting. Compusense Five version 5.2 software (Compusense Inc., Guelph, Canada) was used to generate all random codes, questionnaires and to capture the consumers' responses.

\subsection{Physico-chemical analyses}

The $\mathrm{pH}$ of the low fat UHT milk samples was determined at $25^{\circ} \mathrm{C}$ using an electronic bench $\mathrm{pH}$ meter (Microprocessor pH211, HANNA® products, Italy) with a combination electrode. (AOAC, 2005). Prior to use, the $\mathrm{pH}$ meter was standardized with standard buffer solutions of $\mathrm{pH} 4$ and 7. The titratable acidity was expressed as the \% lactic acid as determined by titration of a known amount of milk with $0.1 \mathrm{~N}$ $\mathrm{NaOH}$ using phenolphythalein as indicator (Hang, 2004).

$\mathrm{L}^{*}, \mathrm{a}^{*}$ and $\mathrm{b}^{*}$-values of the low fat UHT milk was measured using a colour meter (Minolta Chroma meter CR-400, Konica Minolta Sensing, Japan). The colorimetric 
values correspond to measurements based on black-white ( $\mathrm{L}^{*}$ - value scale of 0 $100)$, red to green ( $\mathrm{a}^{*}$ - value scale from positive to negative results), and yellow to blue ( $b^{*}$ - value also scale from positive to negative results). The colour meter was calibrated using a white colour tile standard supplied by the manufacturer and the milk volume was adjusted $(10 \mathrm{~mL})$ so the measuring head just touched the surface of the sample.

The method of Keeney and Bassette (1958) was used to measure free and total HMF in milk samples. The results were expressed as micromoles HMF.L ${ }^{-1}$ UHT milk.

\subsection{Enzymatic reactions}

Proteolysis in the UHT milk was measured by quantifying the primary amino groups using the trinitrobenzene sulfonic acid method described by McKellar et al. (1981). Results were expressed as mg glycine. $\mathrm{mL}^{-1}$ UHT milk.

Lipolysis in the UHT milk was determined by the acid degree value as described by Thomas, Nielson, and Olson (1955). The results were expressed as $\mathrm{mL}$ of $1 \mathrm{~N}$ base required to neutralize the acids in $100 \mathrm{~g}$ of fat.

\subsection{Statistical analysis of the data}

\subsubsection{Survival analysis}

Survival analysis methodology was used to determine the shelf life of UHT milk stored at $25^{\circ} \mathrm{C}$, using the results obtained from consumers when asked if they would normally consume the samples at the different storage times. The exact storage time at which the consumer rejects the milk sample $(T)$ could not be observed due to a limited number of samples with different storage times that were evaluated. Different types of censoring could therefore be expected from consumer shelf life studies

(Hough et al., 2003). If it is presumed that consumers are presented with samples stored at times $t 1, t 2$ and $t 3$ and a consumer rejects the sample at the first storage time, the point of rejection for that consumer will not be observed since it is before the first storage time $(T \leq t 1)$ and the data are left censored, value smaller than the 
first storage time. If the consumer accepts the sample stored for $t 1$ but rejects the sample stored for $t 2$, the data will be interval censored and the exact time at which the consumer rejects the product occurs between $t 1$ and $t 2(t 1<T \leq t 2)$. Finally, if the consumer accepts all the samples, the point of rejection is presumed to be after the last storage time observed $(T>t 3)$ and the data is right censored, value larger than the last storage time. Parametric models, including log-linear, log-normal, Weibull, logistic, Gaussian, log-logistic and exponential models, were used to obtain precise estimates of the survival function (Klein \& Moeschberger, 1997). To estimate the shelf life of the low fat UHT milk, the probability of a consumer rejecting the product must be chosen. Although the point of $50 \%$ rejection by consumers is most used (Hough, Garitta, \& Gómez, 2006; Varela, Salvador, \& Fiszman, 2005), a more conservative level of 25\% (Gámbaro et al., 2006) or even both (Araneda, Hough, \& De Penna, 2008) have been reported. In the present study, the shelf-life was estimated for $50 \%$ consumer rejection. Various distributions were fitted to the data using R statistical software (R Development Core team, 2010). Only data from consumers that did not reject the freshest sample (120 days) were included in the analysis (Hough et al., 2006).

\subsubsection{Hedonic ratings for liking and physico-chemical analysis}

Analysis of variance (ANOVA) was performed on the hedonic ratings for aroma, taste, aftertaste and overall liking scores considering consumers as random and samples of various ages as fixed sources of variation. Mean ratings were calculated and the Fisher Least Significant Difference (LSD) test was used to investigate the nature of these differences using Statistica Version 10.0 (Statsoft, Tulsa, USA).

All the physico-chemical and enzymatic experiments were performed in triplicate and data obtained was analysed by one-way ANOVA. Mean ratings were calculated and the Fisher Least Significant Difference (LSD) test was used to investigate the nature of these differences. 


\subsubsection{Check-all-that-apply (CATA) data analysis}

In order to evaluate whether the consumers were able to detect significant differences among the low fat UHT milk samples of different ages, Cochran's Q test, with multiple pairwise comparisons using the McNemar approach, was carried out for each of the attributes of the CATA question (Parente, Manzoni, \& Ares, 2011). Frequency of mention for each word of the CATA question was determined by counting the number of consumers who used that word to describe each low fat UHT milk sample.

Then, in order to get a bi-dimensional representation of the samples, correspondence analysis (CA) was used on a matrix containing the number of consumers who checked each term from the CATA question to describe each sample. Physicochemical and enzymatic data were considered as supplementary variables. This analysis provides a sensory map of the samples, which enables one to determine the similarities and differences among the samples (Ares et al., 2010)

\section{RESULTS AND DISCUSSION}

\subsection{Survival analysis}

To determine the end of shelf-life, survival analysis was used. For the survival analysis data, the following standard distributions were compared: Weibull, logistic, Gaussian, log-logistic, log-normal and exponential (Table 1). Survival analysis of the data showed that the log-logistic and log-normal distributions adjusted well to the shelf-life data when the lowest absolute log-likelihood value was taken as criteria in choosing among the distributions (Hough, 2010). Based on this criterion, the lognormal distribution fitted the data best and was chosen to model the rejection of low fat UHT milk stored at $25^{\circ} \mathrm{C}$ (Fig. 1).

With the end of shelf-life set at the point where $50 \%$ of the consumers who had accepted the freshest sample rejected the product, the log-normal distribution (Fig. 1) gave a predicted shelf-life of 214 d, with lower and upper confidence levels of 205 and $223 \mathrm{~d}$, respectively. This compares well with the results from the multivariate accelerated shelf life test (MASLT) that estimated the shelf life of the low fat UHT milk at $211( \pm 7)$ d (Richards et al., 2014). 


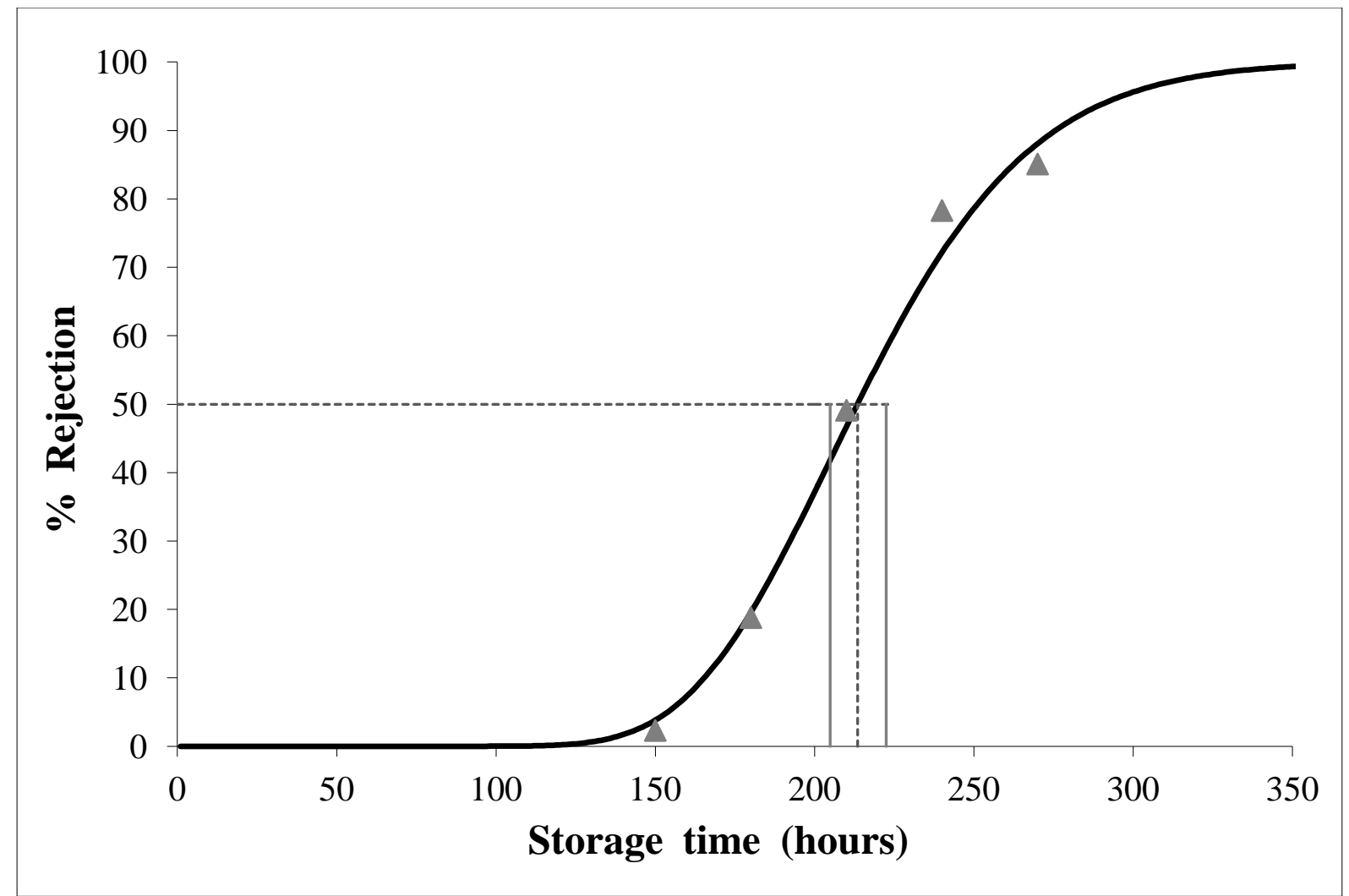

Figure 1: Percentage of consumers rejecting the product versus storage time. 50\% rejection points $=$ dotted line, $95 \%$ confidence intervals $=$ grey solid lines, nonparametric data points $=$ triangles. 
Table 1: Comparison of log-likelihood values from different standard statistical distribution curves to determine the best fit to the low fat UHT milk shelf-life data.

\begin{tabular}{ll}
\hline Model & Log-likelihood \\
\hline Weibull & 137.5 \\
Logistic & 135.4 \\
Gaussian & 135.8 \\
Log-logistic & 132.6 \\
Log-normal & 132.5 \\
Exponential & 198.4 \\
\hline
\end{tabular}




\subsection{Consumers' liking and CATA}

When consumers were asked to score the UHT milk samples with different storage times on hedonic scales, significant differences were found in consumers' aroma, appearance, flavour and overall liking scores (Table 2). The consumers' aroma and appearance liking scores were high for the freshest milk sample (120 d) and then progressively decreased with storage. Both the flavour and overall liking scores were very similar over time and significant differences were only recorded for samples at 150 and $240 \mathrm{~d}$. This may be an indication that flavour plays the biggest role in the overall liking of the samples. The significant differences in the consumers' liking scores suggest changes in the low fat UHT milk over time. This may be due to a decrease in the sensory quality of the milk as a result of various physico-chemical and biochemical changes that occur in the milk after processing (Datta \& Deeth, 2003).

Table 3 shows the frequency with which each of the sensory attributes in the CATA question was used to describe the low fat UHT milk of different ages. Consumers checked between 1 and 15 sensory attributes to describe the low fat UHT milk presented to them. The most frequently used attributes, included white colour, fresh milk aroma, creamy taste and sweet taste, and were all positive or desirable attributes associated with fresh UHT milk (Richards et al., 2014), while the least-used attributes were negative or undesirable attributes like curdling, sour taste, bitter taste, metal taste and off-smell. Significant differences were found in the frequencies with which nine of the 16 CATA attributes were used to describe the UHT milk samples. From this table we can also see that the frequency with which the positive and negative attributes were selected decreased and increased, respectively, as the milk aged. This may be an indication that not only the increase in negative attributes, but also a decrease in positive attributes or a combination of the two may have an influence on consumer acceptance of the low fat UHT milk.

Results from the liking scores and CATA question indicate that the sensory quality of the milk deteriorates over time. This coincides well with literature that states that different aroma, flavour and textural changes occur in UHT milk during storage and 
Table 2: Mean consumers' aroma, appearance, flavour and overall liking scores as rated on a 9-point hedonic scale ${ }^{1}$ for low fat UHT milk samples stored at $25^{\circ} \mathrm{C}$ for different storage times $(n=120)$.

\begin{tabular}{lllll}
\hline Storage time & Aroma & Appearance & Flavour & Overall liking \\
\hline $\mathbf{1 2 0} \mathbf{d}$ & $7.3(1.5)^{\mathrm{f}}$ & $7.3(1.0)^{\mathrm{d}}$ & $7.6(1.4)^{\mathrm{e}}$ & $7.5(1.4)^{\mathrm{e}}$ \\
$\mathbf{1 5 0} \mathbf{d}$ & $6.5(1.5)^{\mathrm{e}}$ & $7.1(1.0)^{\mathrm{cd}}$ & $7.3(1.6)^{\mathrm{d}}$ & $7.4(1.4)^{\mathrm{d}}$ \\
$\mathbf{1 8 0} \mathbf{d}$ & $6.1(1.6)^{\mathrm{d}}$ & $7.1(1.1)^{\mathrm{cd}}$ & $6.6(1.7)^{\mathrm{c}}$ & $6.7(1.4)^{\mathrm{c}}$ \\
$\mathbf{2 1 0} \mathbf{d}$ & $5.7(1.7)^{\mathrm{c}}$ & $7.0(1.3)^{\mathrm{c}}$ & $6.1(1.7)^{\mathrm{b}}$ & $6.2(1.4)^{\mathrm{b}}$ \\
$\mathbf{2 4 0} \mathbf{d}$ & $5.3(1.8)^{\mathrm{b}}$ & $6.4(1.4)^{\mathrm{b}}$ & $5.6(1.8)^{\mathrm{a}}$ & $5.7(1.3)^{\mathrm{a}}$ \\
$\mathbf{2 7 0} \mathbf{d}$ & $4.9(1.8)^{\mathrm{a}}$ & $6.1(1.4)^{\mathrm{a}}$ & $4.8(1.7)^{\mathrm{a}}$ & $4.8(1.7)^{\mathrm{a}}$ \\
\hline
\end{tabular}

${ }^{1}$ with 1 being "like extremely" and 9 being "dislike extremely"

*Values with same superscripts in columns represent no significant differences ( $p>0.05$ ).

*Standard deviations shown in parenthesis. 
Table 3: CATA (check-all-that-apply) frequency table for different attributes of UHT milk samples stored at $25^{\circ} \mathrm{C}$ for different storage times $(n=120)$.

\begin{tabular}{|c|c|c|c|c|c|c|}
\hline \multirow[t]{2}{*}{ Attribute } & \multicolumn{6}{|c|}{ Milk with different storage times (days) } \\
\hline & 120 & 150 & 180 & 210 & 240 & 270 \\
\hline Caramel smell & $11^{\mathrm{a}}$ & $11^{\mathrm{a}}$ & $15^{\mathrm{ab}}$ & $19^{\mathrm{ab}}$ & $20^{\mathrm{ab}}$ & $26^{b}$ \\
\hline Cooked milk smell & $20^{\mathrm{a}}$ & $21^{\mathrm{a}}$ & $21^{\mathrm{a}}$ & $21^{\mathrm{a}}$ & $22^{\mathrm{a}}$ & $23^{\mathrm{a}}$ \\
\hline Fresh milk smell & $64^{\mathrm{c}}$ & $57^{\mathrm{b}}$ & $48^{\mathrm{ab}}$ & $40^{\mathrm{a}}$ & $36^{\mathrm{a}}$ & $34^{\mathrm{a}}$ \\
\hline Sour smell & $8^{\mathrm{a}}$ & $9^{\mathrm{ab}}$ & $9^{\mathrm{ab}}$ & $14^{\mathrm{b}}$ & $21^{\mathrm{b}}$ & $26^{\mathrm{b}}$ \\
\hline Off smell & $11^{\mathrm{a}}$ & $12^{\mathrm{a}}$ & $12^{\mathrm{a}}$ & $12^{\mathrm{a}}$ & $17^{\mathrm{a}}$ & $18^{\mathrm{a}}$ \\
\hline Caramel taste & $13^{\mathrm{a}}$ & $13^{\mathrm{a}}$ & $15^{\mathrm{a}}$ & $18^{\mathrm{ab}}$ & $22^{\mathrm{ab}}$ & $27^{\mathrm{b}}$ \\
\hline Cooked milk taste & $23^{\mathrm{a}}$ & $25^{\mathrm{a}}$ & $25^{\mathrm{a}}$ & $27^{\mathrm{a}}$ & $34^{\mathrm{a}}$ & $35^{\mathrm{a}}$ \\
\hline Sweet taste & $46^{c}$ & $43^{\mathrm{bc}}$ & $33^{\mathrm{abc}}$ & $32^{\mathrm{abc}}$ & $31^{\mathrm{ab}}$ & $30^{\mathrm{a}}$ \\
\hline Sour taste & $10^{\mathrm{a}}$ & $10^{\mathrm{a}}$ & $10^{\mathrm{a}}$ & $11^{\mathrm{a}}$ & $12^{\mathrm{a}}$ & $14^{\mathrm{a}}$ \\
\hline Off taste & $8^{\mathrm{a}}$ & $8^{\mathrm{a}}$ & $18^{\mathrm{b}}$ & $21^{\mathrm{b}}$ & $21^{\mathrm{b}}$ & $22^{\mathrm{b}}$ \\
\hline Creamy taste & $42^{\mathrm{a}}$ & $45^{\mathrm{a}}$ & $43^{\mathrm{a}}$ & $42^{\mathrm{a}}$ & $42^{\mathrm{a}}$ & $41^{\mathrm{a}}$ \\
\hline Bitter taste & $7^{\mathrm{a}}$ & $8^{\mathrm{ab}}$ & $13^{\mathrm{abc}}$ & $16^{\mathrm{bc}}$ & $16^{\mathrm{bc}}$ & $18^{\mathrm{c}}$ \\
\hline Dry mouth feel & $11^{\mathrm{a}}$ & $12^{\mathrm{a}}$ & $15^{\mathrm{ab}}$ & $20^{\mathrm{ab}}$ & $22^{\mathrm{ab}}$ & $24^{\mathrm{b}}$ \\
\hline Metal taste & $11^{\mathrm{a}}$ & $13^{\mathrm{a}}$ & $13^{\mathrm{a}}$ & $14^{\mathrm{a}}$ & $15^{\mathrm{a}}$ & $15^{\mathrm{a}}$ \\
\hline White colour & $73^{\mathrm{a}}$ & $69^{a}$ & $65^{\mathrm{a}}$ & $64^{\mathrm{a}}$ & $62^{\mathrm{a}}$ & $60^{\mathrm{a}}$ \\
\hline Curdling & $2^{\mathrm{a}}$ & $2^{\mathrm{a}}$ & $2^{\mathrm{a}}$ & $6^{\mathrm{a}}$ & $15^{\mathrm{b}}$ & $16^{\mathrm{b}}$ \\
\hline
\end{tabular}

* Values with different superscripts in rows represent significant differences $(\mathrm{p}<0.05)$. 
ultimately limits the shelf-life of the milk. These changes include a decrease in favourable attributes associated with the milk, e.g. the decrease in the sweet aroma and taste in UHT milk (Clare et al., 2005), and an increase in unfavourable attributes, e.g. off-flavour development and gelation (Shipe et al., 1978; Celestino et al., 1997; Borle, et al., 2001).

By 214 days (the survival analysis threshold) the consumers' aroma, appearance, flavour and overall liking scores have decreased significantly. The frequency with which the positive attributes were selected in the CATA question decreased significantly, while the negative attribute selection increased significantly.

\subsection{Physico-chemical and enzymatic reactions}

All the physico-chemical reactions showed significant changes with increasing storage time (Table 4). A definite effect of storage time on $\mathrm{pH}$ was detected for milk stored for 120 and $270 \mathrm{~d}$. The maximum $\mathrm{pH}$ of 6.7 was recorded at $120 \mathrm{~d}$, while the lowest $\mathrm{pH}$ of 6.5 was recorded at $270 \mathrm{~d}$. Andrews, Brooker, and Hobbs (1977) reported that the level and extent of $\mathrm{pH}$ decrease was related to age gelation of the milk. The casein micelles in milk are stable at $\mathrm{pH}$ 6.7. Below this $\mathrm{pH}$ level aggregation of the micelles occurs and this may result in some consistency defects. Milk stored for 240 and 270 days also showed some clotting as indicated by the consumers in the CATA question, and this may be due to a reduced $\mathrm{pH}$. A slight increase in the titratable acidity, from 0.18 to $0.21 \%$ lactic acid, was noted during storage of the UHT milk. After high temperature treatment and subsequent storage, lactose is degraded to acids that are responsible for an increase in the titratable acidity of the milk (Swartzel, 1983).

Browning caused by the Maillard reaction, was measured by total and free HMF present in the milk and showed an increase over time, with the levels of total and free HMF increasing from 6.21 to 11.40 and 1.37 to 3.88 , respectively. Vankatachalm and McMahon (1991) verified a drop in the $\mathrm{pH}$ and associated it with browning reactions that take place in the milk. The Maillard reaction is also a source of volatile sulphur compounds in heated milk (Badings, Neeter, \& Van Der Pol, 1978; Calvo \& De la Hoz, 1992), which are in turn responsible for the cooked flavour in 
Table 4: Physico-chemical and enzymatic parameters measured in low fat UHT milk stored at $25^{\circ} \mathrm{C}$ for various storage times.

\begin{tabular}{|c|c|c|c|c|c|c|}
\hline Storage time $(d)$ & 120 & 150 & 180 & 210 & 240 & 270 \\
\hline \multicolumn{7}{|l|}{ Physico-chemical parameters } \\
\hline \multirow{2}{*}{$\mathrm{pH}$} & 6.70 & 6.68 & 6.65 & 6.64 & 6.56 & 6.50 \\
\hline & $(0.02)^{\mathrm{d}}$ & $(0.01)^{\mathrm{d}}$ & $(0.02)^{\mathrm{c}}$ & $(0.01)^{\mathrm{c}}$ & $(0.01)^{\mathrm{b}}$ & $(0.02)^{\mathrm{a}}$ \\
\hline Titratable acidity (\% lactic & 0.18 & 0.18 & 0.19 & 0.19 & 0.20 & 0.21 \\
\hline acid) & $(0.00)^{\mathrm{a}}$ & $(0.00)^{\mathrm{a}}$ & $(0.00)^{\mathrm{b}}$ & $(0.01)^{\mathrm{bc}}$ & $(0.01)^{\mathrm{cd}}$ & $(0.01)^{\mathrm{d}}$ \\
\hline Total hydroxymethylfurfural & 6.21 & 7.93 & 8.93 & 10.27 & 11.62 & 11.40 \\
\hline$\left(\right.$ HMF.L $\left.L^{-1}\right)$ & $(0.66)^{\mathrm{a}}$ & $(0.51)^{\mathrm{b}}$ & $(0.15)^{\mathrm{b}}$ & $(0.48)^{\mathrm{c}}$ & $(0.26)^{\mathrm{c}}$ & $(0.15)^{\mathrm{d}}$ \\
\hline \multirow[t]{2}{*}{ Free HMF (HMF.L $\left.{ }^{-1}\right)$} & 1.37 & 1.55 & 2.04 & 2.53 & 3.25 & 3.88 \\
\hline & $(0.25)^{\mathrm{a}}$ & $(0.24)^{\mathrm{a}}$ & $(0.13)^{\mathrm{ab}}$ & $(0.09)^{\mathrm{b}}$ & $(0.20)^{\mathrm{c}}$ & $(0.28)^{\mathrm{c}}$ \\
\hline \multirow[t]{2}{*}{$\mathrm{L}^{*}$} & 87.33 & 86.97 & 86.45 & 86.02 & 85.87 & 85.54 \\
\hline & $(0.02)^{\mathrm{d}}$ & $(0.06)^{\mathrm{d}}$ & $(0.04)^{\mathrm{c}}$ & $(0.17)^{\mathrm{b}}$ & $(0.14)^{\mathrm{ab}}$ & $(0.11)^{\mathrm{a}}$ \\
\hline \multirow[t]{2}{*}{$a^{*}$} & -3.57 & -3.46 & -3.33 & -3.16 & -3.09 & -2.97 \\
\hline & $(0.03)^{\mathrm{d}}$ & $(0.01)^{\mathrm{cd}}$ & $(0.07)^{\mathrm{c}}$ & $(0.05)^{\mathrm{b}}$ & $(0.10)^{\mathrm{ab}}$ & $(0.05)^{\mathrm{a}}$ \\
\hline \multirow[t]{2}{*}{$b^{*}$} & 5.84 & 6.12 & 6.26 & 6.57 & 6.71 & 6.90 \\
\hline & $(0.05)^{\mathrm{d}}$ & $(0.02)^{\mathrm{cd}}$ & $(0.07)^{\mathrm{c}}$ & $(0.06)^{b}$ & $(0.11)^{\mathrm{b}}$ & $(0.08)^{\mathrm{a}}$ \\
\hline \multicolumn{7}{|l|}{ Enzymatic parameters } \\
\hline Lipolysis & 1.60 & 2.00 & 2.27 & 2.40 & 2.57 & 2.70 \\
\hline$\left(\mathrm{mg} \mathrm{NaOH} .100 \mathrm{~g}^{-1}\right.$ fat) & $(0.10)^{\mathrm{a}}$ & $(0.20)^{\mathrm{ab}}$ & $(0.31)^{\mathrm{bc}}$ & $(0.00)^{\mathrm{bc}}$ & $(0.15)^{\mathrm{d}}$ & $(0.10)^{d}$ \\
\hline Proteolysis & 0.05 & 0.05 & 0.06 & 0.06 & 0.08 & 0.10 \\
\hline (mg glycine. $\mathrm{mL}^{-1}$ ) & $(0.00)^{\mathrm{a}}$ & $(0.00)^{\mathrm{a}}$ & $(0.01)^{\mathrm{b}}$ & $(0.01)^{\mathrm{b}}$ & $(0.00)^{\mathrm{c}}$ & $(0.01)^{\mathrm{d}}$ \\
\hline
\end{tabular}

*Values expressed as mean values with standard deviation in parenthesis. Values with different superscripts in rows represent significant differences $(p<0.05)$. Three replicates were used for data analysis. 
UHT milk (Badings, 1991; Patrick \& Swaisgood, 1976). Colour is an important parameter in UHT milk that may affect consumer acceptability. The Maillard reaction consists of a series of chemical reactions resulting in the formation of brown-coloured pigments, such as pyralysins and melanoidins, low molecular weight acids, as well as polymers, such as lactulose-lysine and fructose-lysine (Cattaneo, Masotti, \& Pellegrino, 2008). This may explain the change in colour of the UHT milk over time.

Even though microorganisms are inactivated by UHT treatment, some heat-resistant enzymes of native and bacterial origin can survive and cause both flavour and consistency defects in the milk during storage (Burton, 1988; Valero et al., 2001). The levels of both proteolysis and lipolysis in the UHT milk increased over time. Proteolysis can result in age gelation of UHT milk by hydrolysing the caseins and releasing the $\beta$-lactoglobulin- $\kappa$-casein complex ( $\beta \kappa$-complex) that is formed during heat treatment, from the micelle. Subsequent aggregation of these complexes causes the milk to gel (McMahon, 1996). Proteolysis also causes the development of off-flavours, such as bitterness, in the milk due to the release of tyrosine in the milk (GebreEgziabher, Humbert, \& Blankenagel, 1980). Both the increase in curdling and bitter taste recorded by the consumers for older milk samples may b e due to proteolysis of the milk. Lipolysis of milk triacylglycerols causes off-flavours in the milk due to the release of short- and medium-chain fatty acids (Choi \& Jeon, 1993). Free fatty acids released during lipolysis are also precursors for other flavour compounds, like esters and methyl ketones, while unsaturated fatty acids are susceptible to oxidation and the formation of ketones and aldehydes responsible for metallic and cardboard flavours in the milk (Vulfson, 1994). Free fatty acids are also responsible for the increase in titratable acidity of milk (Swartzel, 1983).

\subsection{Correspondence analysis}

Data collected in the CATA question was used to construct a correspondence analysis (CA) plot, considering physico-chemical and enzymatic data as supplementary variables (Fig. 2). The first and second dimension of the correspondence analysis calculated from the CATA counts accounted for $90 \%$ and $8 \%$ of the variance of the experimental data, respectively. Fresher milk on the right hand side of the plot is separated from older milk on the left. The fresh milk samples (D120 and D150) are 


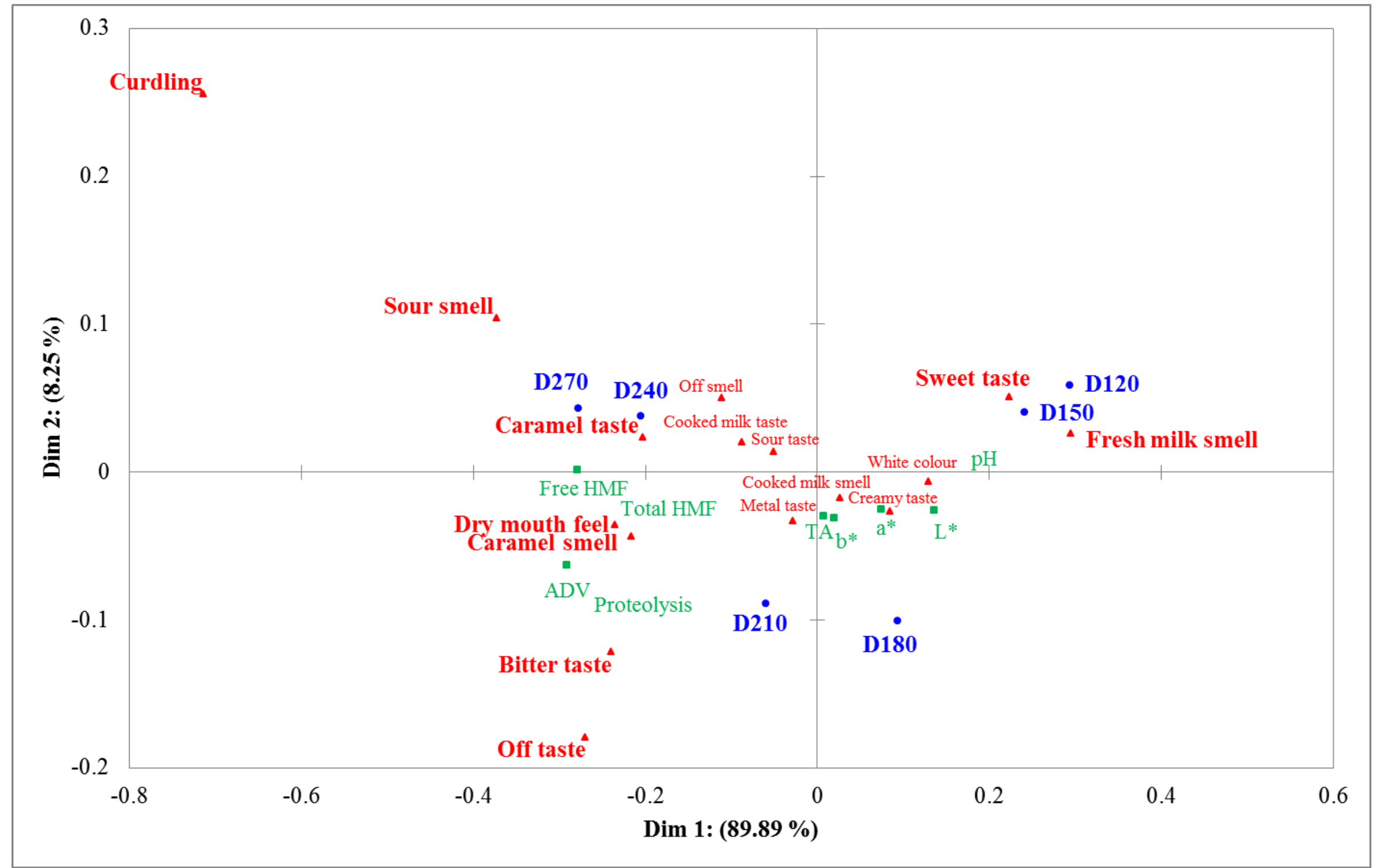

Figure 2: Correspondence analysis plot representing the sensory attributes (red) of the CATA question on the first two dimensions for low fat UHT milk stored at $25^{\circ} \mathrm{C}$ for different time periods (D, blue). Sensory attributes that showed significant change over time are in bold. Supplementary data include the physico-chemical and enzymatic data (green). $(n=120)$. 
described by sweet taste and fresh milk smell, typically what we would expect for the fresher samples, while in the top left corner we have the two oldest samples (D240 and D270) that were described by more negative attributes like caramel taste, sour smell and curdling.

Furthermore, using CA some correlations among sensory attributes and physicochemical variables could be visualised. As shown in Fig. 2 total HMF and free HMF, were positively correlated with the attributes caramel smell and caramel taste and negatively with the attribute fresh milk smell. Proteolysis was also positively correlated with the CATA attribute bitter, whereas $\mathrm{L}^{*}$ was positively correlated with the attribute white colour. These results show that consumers' selection of CATA attributes to describe the milk was in agreement with the physico-chemical differences among the samples. In addition, fresher samples were associated with higher $\mathrm{pH}$ values, while the older samples were associated with higher acid degree values (ADV), higher levels of proteolysis and higher levels of free and total HMF.

\section{CONCLUSIONS}

Survival analysis can be used to successfully determine the shelf life of low fat UHT milk. The shelf life of the UHT milk based on consumers accepting or rejecting the samples with a 50\% rejection rate was determined to be $214( \pm 9)$ d. This shelf life determined by survival analysis coincides well with the shelf life determined using the MASLT, which was estimated at $211( \pm 7)$ d (Richards et al., 2014). The shelf life determined by survival analysis therefore validated that determined by the MASLT in a previous study.

Data from consumer liking, profiling, physico-chemical parameters and enzymatic parameters showed significant changes in the low fat UHT milk over time. As the consumer liking of the aroma, appearance, taste and overall liking decreased, the detection of positive attributes in the milk decreased, while the detection of negative attributes increased. Physico-chemical and enzymatic parameters associated with deterioration of UHT milk also increased over time. 


\section{Acknowledgments}

The South African National Research Foundation (NRF) Technology and Human Resource Programme (THRIP) (Grant TP 2010071400012) for providing financial support for this study.

\section{REFERENCES}

Andrews, A.T., Brooker, B.E., \& Hobbs, D.G. (1977). Properties of aseptically packed UHT milk. Electron microscopic examination of changes occurring during storage. Journal of Dairy Research 44, 283-285. AOAC (2005). Official methods of analysis of the association of official analytical chemists. 16th edition. 481. Gaithersburg, MD, USA: Association of Official Analytical Chemists International.

Araneda, M., Hough, G. \& De Penna, E.W. (2008). Current-status survival analysis methodology applied to estimating sensory shelf life of ready-to-eat lettuce (Lactuca sativa). Journal of Sensory Studies 23, 162-170.

Ares, G., Barreiro, C., Deliza, R., Giménez, A., \& Gámbaro, A. (2010). Application of a check-all-that-apply question to the development of chocolate milk desserts. Journal of Sensory Studies, 25, 67-86. Badings, H.T., Neeter, R., \& Van Der Pol, J.J.G. (1978). Reduction of cooked flavour in heated milk and milk products by 1-cystine.

Lebensmittel-Wissenschaft and Technology, 11, 237-240.

Badings, H.T. (1991). Milk. In H. Maarse (Ed), Volatile Compounds in Foods and Beverage (pp. 91-106). New York, USA: Marcel Dekker. Borle, F., Sieber, R. \& Bosset, J.O. (2001). Photo-oxidation and photoprotection of foods, with particular reference to dairy products: An update of a review article. Science Aliments, 21, 571-590.

Burton, H. (1988). Ultra-high-temperature processing of milk and milk products. New York, USA: Elsevier Applied Science Publications Inc. Calvo, M.M., \& De La Hoz, L. (1992). Flavour of heated milks. A review. International Dairy Journal, 2, 69-81. 
Cardelli, C., \& Labuza, T.P. (2001). Application of Weibull hazard analysis to the determination of the shelf-life of roasted and ground coffee. Lebensmittel-Wissenschaft Technology, 34, 273-278.

Cattaneo, S., Masotti, F., \& Pellegrino, L. (2008). Effects of overprocessing on heat damage of UHT milk. Eurapean Food Research and Technology, 226, 1099-106.

Celestino, E.L., Iyer, M., \& Roginski, H. (1997). Reconstituted UHT-treat milk: Effects of raw milk, powder quality and storage conditions of UHT milk on its physico-chemical attributes and flavour. International Dairy Journal, 7, 129-140.

Choi, W., \& Jeon I.J. (1993). Patterns of fatty acids released from milk fat by residual lipase during storage of ultra-high temperature processed milk. Journal of Dairy Science, 76, 78-85.

Clare, D.A., Bang, W.S., Cartwright, G., Drake, M.A., Coronel, P. \& Simunovic, J. (2005). Comparison of sensory, microbiological, and biochemical parameters of microwave verses indirect UHT fluid skim milk during storage. Journal of Dairy Science, 88, 4172-4182.

Corrigan, V., Hedderley, D. \& Harvey, W. (2012). Modeling the shelf-life of fruit-filled snack bars using survival analysis and sensory profiling techniques. Journal of Sensory studies, 27, 403-416.

Curia, A., Aguerrido, M., Langohr, K. \& Hough, G. (2005). Survival analysis applied to sensory shelf-life of yogurts, I. Argentine formulations. Journal of Food Science, 70, 442-445.

Datta, N., \& Deeth, H. C. (2003). Diagnosing the cause of proteolysis in UHT milk. Food Science and Technology, 36, 173-182.

Gámbaro, A., Garitta, L., Giménez, A., Varela, P. \& Hough, G. (2004). Sensory shelf-life estimation of "alfajor" by survival analysis. Journal of Sensory Studies, 19, 500-509.

Gámbaro, A., Ares, G. \& Giménez, A. 2006. Shelf-life estimation of apple baby food. Journal of Sensory Studies, 21, 101-111.

Garitta, L., Hough, G. \& Sánchez, R. (2004). Sensory shelf-life of dulce de leche. Journal of Dairy Science, 87, 1601-1607. 
Gebre-Egziabher, A., Humbert, E.S., \& Blankenagel, G. (1980). Hydrolysis of milkproteins by microbial enzymes. Journal of Food Protection, 43, 709-712.

Guerra, S., Lagazio, C., Manzocco, L., Barnaba, M. \& Cappuccio, R. (2008). Risks and pitfalls of sensory data analysis for shelf-life prediction, Data simulation applied to the case of coffee. LWT-Food Science and Technology, 41, 2070-2078.

Hang, Y.D. (2004). Sauerkraut. In Hui, Y.H., Meunier-Goddik, L., Hansen, A.S., Josephsen, J., Nip, W., Stanfield, P.S., \& Toldra, F. (Eds). Handbook of food and beverage fermentation technology (pp. 669-676). New York. US: CRC Press.

Hough, G. (1998). Experts versus comsumers: a critique. Journal of Sensory Studies, 13, 285-289.

Hough, G., Langhour, K., Gomez, G. \& Curia, A. (2003). Survival analysis applied to sensory shelf-life of foods. Journal of Food Science, $68, \quad 359-362$.

Hough, G., Garitta, L. \& Gómez, G. (2005). Sensory shelf-life predictions by survival analysis accelerated storage models. Food Quality and Preference, 17: 468-473.

Hough, G., Garitta, L., \& Gómez, G. (2006). Sensory shelf-life predictions by survival analysis accelerated storage models. Food Quality and Preference, 17, 468-473.

Hough, G., Luz Calle, M., Serrat, C. \& Curia, A. (2007). Number of consumers necessary for shelf life estimations based on survival analysis statistics. Food Quality and Preference, 18, 771-775.

Hough, G. 2010. Sensory shelf-life estimation of food products. London, UK: CRC Press.

Keeney, M., \& Bassette, R. (1958). Detection of intermediate compounds in the early stages of browning reaction in milk products. Journal of Dairy Science, 42, 945-960.

Klein, J. P., \& Moeschberger, M. L. (1997). Survival analysis, techniques for censored and truncated data. New York, NY, USA: Springer-Verlag. Lawless, H.T. \& Claassen, M.R. (1993). Validity of descriptive and defect-oriented terminology systems for sensory analysis of fluid milk. Journal of Food Science, 58, 108-112. 
Lawless, H.T. \& Heymann, H. 1998. Sensory Evaluation of Food:

Principles and Practices. Gaithersburg, MD, USA: Aspen Publications.

McKellar, R.C. (1981). Development of off-flavour in Ultra-High

Temperature and Pasteurised Milk as a function of proteolysis. Journal of Dairy Science, 64, 2138-2145.

McMahon, D. J. (1996). Age-gelation of UHT milk: Changes that occur during storage, their effect on shelf life and the mechanism by which age-gelation occurs. In IDF Symposium, Vienna, Heat treatments and alternative methods (pp. 315-326). Brussels, Belgium: International Dairy Federation.

Moskowitz, H. (1998). Consumers versus experts in the light of psychophysics: A reply to Hough. Journal of Sensory Studies, 13, 291298.

Parente, M. E., Manzoni, A. V., \& Ares, G. (2011). External preference mapping of commercial anti-aging creams based on consumers' responses to a check-all-that-apply question. Journal of Sensory Studies, 26, 158-166. Patrick, P. S. and Swaisgood, H. E. (1976). Sulfhydryl and disulphide groups in skim milk as affected by direct ultra-high-temperature heating and subsequent storage. Journal of Dairy Science, 59, 594-600.

R Development Core Team. (2010). R: A Language and environment for statistical computing. Vienna, Austria: $\mathrm{R}$ Foundation for statistical computing. Richards, M., De Kock, H.L., \& Buys, E.M. (2014). Multivariate accelerated shelf life of low fat UHT milk. International Dairy Journal, $36, \quad 3-45$.

Shipe, W.F., Bassette, R., Deane, D.D., Dunkley, W.L., Hammond, E.G., Harper, W.J., Kleyn, D.H., Morgan, M.E., Nelson, J.H. \& Scanlan, R.A. (1978). Off flavours of milk: nomenclature, standards, and bibliography. Journal of Dairy Science, 61, 855-869.

Swartzel, K.R. (1983). The role of heat exchanger fouling in the formation of sediment in aseptically processed and packed milk. Journal of Food Processing and Prevention, 7, 247-251.

Thomas, E.L., Nielson, A.J., \& Olson, J.C. (1955). Hydrolytic rancidity in milk. American Milk Review, 17, 50-53. 
van Trijp, H.C.M. \& Schifferstein, H.N.J. (1995) Sensory analysis in marketing practice: Comparison and integration. Journal of Sensory Studies, $10, \quad 127-147$

Valero, E., Villamiel, M., Miralles, B., Sanz, J., \& Martinez-Castro, I. (2001). Changes in flavour and volatile components during storage of whole and skimmed UHT milk. Food Chemistry, 72: 51-58.

Vankatachalm, N., \& McMahon, D.J. (1991). Effect of lactose concentration on age-gelation of UHT sterilized skim milk concentrate. Journal of Dairy Science, $\quad 74, \quad 101-107$.

Varela, P., Salvador,A. \& Fiszman, S. (2005). Shelf-life estimation of "Fuji" apples: Sensory characteristics and consumer acceptability. Postharvest Biology and Technology, 38, 18-24.

Vulfson, E.N. (1994) Industrial applications of lipases. In Woolley, P., \& Peterson, S.B. (Eds) Lipases-their structure, biochemistry and applications (pp. 271-288). Cambridge, UK: Cambridge University Press.

Williams, E.J. (1949). Experimental designs balanced for the estimation of residual effects of treatments. Australian Journal of Scientific Research, 2, $149-168$ 